\title{
ARTIKKELIT
}

Ville Suuronen

\section{Hannah Arendt kulttuurista ja taiteesta}

\section{Hannah Arendt on culture and art}

This article examines Hannah Arendt as thinker of cultural policy by focusing on her reflections on culture and art. Even though Arendt is known primarily as a political theorist one can also read hear work in a broader sense as a philosophy of culture. This article discusses how Arendt's various narratives of Western history are animated by the attempt to explain how we can come to terms with our fragmented past after what Arendt calls the breakdown of the Western cultural tradition in the modern age. The meaning of culture, narrativity and art as concepts for Arendt as well as her analysis of various art forms are dealt with in detail. I focus especially on the narrative and metaphorical aspects of art and philosophy in Arendt's writings.

Keywords: Hannah Arendt, culture, politics, art, narrativity.

\section{Johdanto}

Politiikan teoreetikkona tunnettua Hannah Arendtia voidaan perustellusti lukea myös kulttuuripolitiikan teoreetikkona, sekä taiteen analyytikkona. Arendt viittaa taiteilijoihin tuotannossaan jatkuvasti ja hän myös kirjoitti filosofisia henkilökuvia useista taitelijoista ${ }^{1}$. Taidemuodoista Arendtille läheisimpiä ovat erityisesti kirjallisuus ja runous ${ }^{2}$, joskin hänen tuotannostaan ja kirjeenvaihdoistaan löytyy myös satunnaisia huomautuksia esimerkiksi musiikista, maalaustaiteesta ja arkkitehtuurista.

Kulttuurin, taiteen ja taiteilijoiden rooli Arendtin ajattelussa ja henkilökohtaisessa elämässä on merkittävä, vaikkakin vähäisesti tutkimuskirjallisuudessa huomiota saanut teema. Arendtin ajattelun suhdetta on tutkittu ennen kaikkea kirjallisuuteen ja erityisesti suhteessa yksittäisiin taiteilijoihin kuten Herman Brochiin, Franz Kafkaan tai Bertold Brechtiin ${ }^{3}$. Artikkelini tavoitteena on esittää yleiskuva Arendtista kulttuuripoliittisena ajattelijana. Keskityn erityisesti kolmeen aspektiin Arendtin ajattelussa: Ensiksi pureudun Arendtin näkemykseen modernin maailman poliittises- ta ja kulttuurillisesta kriisistä ja pohdin missä mielessä nimenomaan poliitisena ajattelijana tunnettua Arendtia voidaan ylipätään lukea kulttuuripoliittisena ajattelijana tai teoreetikkona. Toiseksi käsittelen Arendtin tärkeimpiin teoksiin sisältyviä narratiiveja länsimaisesta kulttuuri- ja ajatteluhistoriasta. Koska Arendt katsoo, että antiikin Roomasta alkava länsimainen kulttuuri- ja ajattelutraditio tulee päätökseensä 1900-luvulla, on Arendtin ajattelussa on vahva menneisyyspoliittinen näkökulma, joka pyrkii artikuloimaan kuinka kulttuurimenneisyytemme näyttäytyy merkityksellisenä nykymaailmassa. Kolmanneksi tutkin Arendtin näkemystä taiteen luonteesta ja eri taidemuotojen ominaispiirteistä. Esitän, että Arendtin ajattelusta on löydettävissä historiallis-metaforinen tapa viitata taideteoksiin historian valaisijoina. Lopuksi kuvaan lyhyesti Arendtin roolia ja merkittävyyttä kulttuuripoliittisena ajattelijana sekä mahdollisia tulevia kulttuuripoliittisen tutkimuksen suuntaviivoja Arendtin ajattelun näkökulmasta ${ }^{4}$. 


\section{Politiikan ja kulttuurin kriisi modernissa maailmassa}

Hannah Arendtin ajattelua voidaan yleisellä tasolla luonnehtia yrityksenä pohtia niin inhimillisen olemisen ja politiikan ennakkoehtoja kuin niiden luonnetta filosofisesti "viimeisimpien kokemustemme ja pelkojemme näkökulmasta" (vrt. Arendt 1989, 5; Arendt 2015, 14) ${ }^{5}$. Vaikka Arendt on pääasiallisesti tunnettu poliittisesta ajattelustaan, tutkii hän politiikan lisäksi myös ihmisen suhdetta kulttuuriin ja taiteeseen. Arendt korostaa, että taide ja kulttuuri ovat politiikan tavoin julkisen maailman ilmiöitä ja siten läheisesti politiikasta riippuvaisia. (Arendt 2006a, 215).

Arendtia on usein tulkittu ajattelijana, jonka suhde moderniin aikakauteen on äärimmäisen negatiivinen ja yksipuolisen kriittinen. Esimerkiksi George Kateb $(1983,183)$ kutsuu Arendtia "suureksi antimodernistiksi" (great antimodernist) ja hiukan samaan sävyyn, tosin huomattavasti hienostuneemmin argumentoiden, Seyla Benhabib (2003) leimaa Arendtin "vastahakoiseksi modernistiksi" (reluctant modernist).

Nämä näkemykset tuntuvatkin ensinäkemältä täysin perustelluilta. Poliitkan tutkimuksen parissa klassikon asemaan nousseessa teoksessaan The Human Condition Arendt esittää tunnetusti, että moderni aikakausi kärsii kiihtyvällä vauhdilla yhä radikaalimmasta "maailmattomuudesta" (wordlessness), eli julkisen alueen (public realm) ja ihmisten välisen maailman tuhoutumisesta. Arendt erottelee teoksessaan käsitteellisesti modernin aikakauden (the modern age) modernista maailmasta (the modern world). Näistä ensimmäinen alkoi Arendtin mukaan tieteellisesti katsoen 1600-luvulta ja kesti aina 1900-luvun alkuun saakka. Poliittisesti katsoen moderni maailma, jossa nyt elämme, alkoi Arendtin mukaan sen sijaan ensimmäisten ydinräjähdysten myötä. (Arendt 1989, 6, 50-58.)

Modernin aikakauden merkki ei ole Arendtin mukaan "itsestä vieraantuminen" (self-alienation) Karl Marxin tarkoittamassa mielessä, vaan nimenomaan "maailmasta vieraantuminen" (world alienation) (Arendt 1989, 254). Arendt kuvaa maailmaa metaforisesti yhteisenä ja jaettuna pöytänä, joka "yhdistää ja erottelee ihmisiä samanaikaisesti" (Arendt 1989, 52). Inhimillinen oleminen on Arendtin mukaan aina lähtökohtaisesti ja erottamattomasti kiinnittynyt johonkin kulttuurilliseen "suhteiden verkkoon" (web of relations), jolla Arendt tarkoittaa sosiaalisten, juridisten, faktuaalisten, henkilökohtaisen yms. suhteiden lopuntona ja alati muuttuvaa dynaamista verkostoa. Maailman käsite viittaakin Arendtin ajatellussa sekä ihmisen itsensä valmistamaan konkreettisten esineiden muodostamaan faktuaaliseen maailmaan että ihmisten välissä olevaan suhteiden verkostoon. Pääteoksensa saksankielisessä versiossa Arendt kuvaa tätä suhteiden maailmaa termillä "inhimillisten asioiden suhdeverkosto" (Bezugsgewebe menschlicher Angelegenheiten). (Arendt 1989, 183; Arendt 2015, 225.) Juuri ihmisten väliin sijoittuva monitasoinen suhteiden maailma mahdollistaa yksittäisten ihmisten jakaman ja inhimilliselle ymmärtämiskyvylle keskeisen yhteisen aistin (common sense). Moderni maailmattomuus tarkoittaa Arendtille nimenomaan common sensen katoamista - yhteisten ja jaettujen toimintaa ja ajattelua ohjaavien standardien menetystä. (Arendt 1989, 208-209; Arendt 2005, 38; Arendt 2006a, 77; Arendt 2015, 264-265; vrt. Arendt 1978a, 50; Arendt 1994a, 470-471.)

Jaetun maailman tuhoutumisen taustalla on Arendtin mukaan tietty historiallinen kehityskulku. Arendt väittää, että kaikkien sivilisaatioiden perustava ja itsestään selvä ennakkoehto aina antiikista uudelle ajalle saakka oli selkeä erottelu kodin yksityisen ja julkisen poliittisen alueeseen (Arendt 1989, 61). Uudella ajalla muodostuu uudenlainen sosiaalisen alue, mikä sekoittaa nämä kaksi aluetta ja niiden intressit. Se tuo yksityisen poliittisen alueelle ja poliittisen yksityisen alueelle: politiikasta tulee uudella ajalla kollektiivista taloudenhoitoa, kasvotonta asioiden hallintaa ja administraatiota (Arendt 1989, 60). Modernilla aikakaudella itse yksityisen alue on politisoitunut ja korvautunut Arendtin mukaan intiimin sfäärillä, jonka löytäjäksi Arendt nimeää Jean-Jacques Rousseaun. Antiikin maailmalle kodin alue (oikos) merkitsi julkisen alueelle vastakkaista yksityisyyden tilaa ja rauhaa, kun taas intiimin sfääri viittaa ainos- 
taan yksilön mielentiloihin ja -muutoksiin. Modernissa yksityisen alue on kutistunut intiimin alueeksi, joka on viimeinen pakopaikka yhteiskunnan vaikutuksen leviämisen edessä. Toinen keskeinen ero antiikin maailmaan on, että tätä yksityisen alueen modernia versiota ei enää ymmärretä olennaisesti vähempiarvoiseksi kuin julkisen aluetta. (Arendt 1989, 38-39.) Arendt tarkoittaa narratiivinsa sosiaalisen alueen noususta ja intiimin sfäärin synnystä poliittisen lisäksi myös kulttuuripoliittiseksi kertomukseksi:

Runouden ja musiikin ällistyttävä kukoistus 1700-luvun puolivälistä lähes 1800-luvun viimeiselle kolmannekselle, jota säesti romaanin ainoan täysin sosiaalisen taidemuodon - nousu, ja samanaikainen, ei yhtään vähemmän silmiinpistävä julkisten taiteiden - etenkin arkkitehtuutin - rappeutuminen, on riittävä todiste sosiaalisen ja intiimin läheisestä suhteesta (Arendt 1989, 39).

Esseessään "The Crisis in Culture (1961)" Arendt korostaa, että poliittisen alueen merkityksellisyyden katoaminen modernissa maailmassa tarkoittaa myös maailman kulttuurillista rappiota; modernin politiikan kriisi on samalla modernin kulttuurin kriisi, sillä jaetun maailman köyhtyminen vaikuttaa olennaisesti kumpaankin. (Arendt 2006a, 215). Sosiaalisen alueen nousun myötä syntyy Arendtin mukaan myös moderni individualismi. Aluksi vain ylimmillä yhteiskuntaluokilla oli käytössään riittävästi varallisuutta ja vapaa-aikaa uhrattavaksi taiteen pariin. Tämä varhainen yhteiskunta, jonka paradigmaattinen esimerkki ovat Arendtin mukaan eurooppalaisen absolutismin aikakauden hovit, korvautuu modernissa maailmassa massayhteiskunnalla, joka syntyy ilmiönä siinä vaiheessa kun suurin osa väestöstä on vapautettu elämän perustarpeiden huolehtimisesta siinä määrin, että heillä on käytössään vapaa-aikaa kulttuurille. Modernissa maailmassa kulttuuri korvautuu massakultuurilla. (Arendt 2006a, 194-197.)

Arendtin mukaan massayhteiskunnassa taide uhkaa menettää sen historiallisessa mielessä representoivan ja menneisyyttä välittävän elementtinsä - sen kyvyn "liikutella lukijaa tai katsojaa vuosisatojen ylitse" - koska itse taiteesta tulee vain yksi vaihtoarvo muiden joukossa (Arendt 2006a, 199-200). Julkisen alueen kuolema näkyy kulttuurin saralla nimenomaan siinä, että taiteesta ja taideteoksista tulee pelkkää viihdettä: Siinä missä taideteokset ovat Arendtin mukaan ihmisen valmistamia ja kestävyydeltään ainutlaatuisia kulttuurillisia objekteja (cultural objects), koostuu moderni massaviihde ainostaan kulutustavaroista (consumer goods). Arendtin kuuluisa teesi siitä, että modernissa maailmassa ihminen on olennaisesti ainostaan elämän ylläpitämisen vuoksi työskentelevä eläin (animal laborans) heijastuu kaikkein intensiivisimmin juuri siinä, että ihminen ei enää kykene ymmärtämään taidetta muuna kuin yhtenä itse elämänprosessiin kuuluvana momenttina. Modernin massayhteiskunnan kulutustavarat ovat luonteeltaan viihdettä ja niiltä puuttuu kulttuurillisten objektien kyky historialliseen representaatioon sekä niille olemuksellinen kestävyys. (Arendt 2006a, 202-203.)

Politiikan ja kulttuurin kriisiin modernissa maailmassa johtaa Arendtin mukaan edellä mainittujen lisäksi myös modernin aikakauden keskeisin poliittinen ideologia, liberalismi, joka näyttäytyy Arendtille todellista politiikkaa tuhoavan ja ei-poliittisen individualismin sanansaattajana. Arendt pitääkin liberalismia 1900-luvulla syntyvien totalitaaristen hallintojen syntyä selittävänä tekijänä: Liberalismin nousu poliittisena ideologiana selittää totalitaaristen valtioiden syntyä, koska se ymmärtää politiikan pelkkänä välttämättömänä pahana ja toissijaisena inhimillisenä aktiviteettina ${ }^{6}$.

Kuten Andreas Kalyvas huomauttaa, Arendtille liberalismi "oli aina totalitaarista, [koska] se olettaa sellaisen politiikan, talouden ja yhteiskunnan identiteetin, jonka mukaan poliittiset instituutiot ovat vain fasadeja yksityisille intresseille" (Kalyvas 2008, 270-271; Arendt 1994a, 336). Arendtille moderni aikakausi ja sen ymmärys politiikan luonteesta ilmentävät kahta keskeistä ennakkoluuloa (Vorurteile) suhteessa politiikkaan. Yhtäältä nykymaailma ymmärtää politiikan olemassa olon pelkkänä välttämättömyytenä, joka palvelee ainostaan korkeampia, henkilökohtaisia päämääriä, ja toisaalta politiikka näyttäytyy meille "luonnollisena" 
ja ikuisena itsestäänselvyytenä. (Arendt 2010, 11-12; 41-42). Arendtin ajattelun yksi keskeisimmistä lähtökohdista onkin palata länsimaiseen historiaan etsimään vaihtoehtoisia tapoja ja kokemuksia poliittisesta ja tätä kautta pyrkiä ymmärtämään ja käsitteellistämään inhimillistä olemista modernille aikakaudella epäintuitiivisella tavalla.

Vaikka Arendt suhtautuukin modernin aikakauden politiikkaymmärrykseen ja historialliseen kehitykseen äärimmäisen torjuvasti, on hänen leimaaminen "antimoderniksi" (Kateb), tai edes lievemmässä muodossa "vastahakoiseksi modernistiksi" (Benhabib), yleisellä tasolla tavoin kuitenkin harhaanjohtavaa. Kuten Dana Villa $(1996,174)$ huomauttaa, Arendtia ei voida liittää sellaisiin poliittisiin kulttuurikonservatiivisiin ajattelijoihin, jotka yksinkertaiseti haikailevat paluuta esimoderniin aikaan - tällaista simplifikoivaa asennetta ei voida löytää mistään Arendtin teksteistä. Arendtin näennäisen pessimistisestä filosofisesta aikalaisdiagnoosista löytyykin vahvan positiivinen pohjavire, jossa voidaan nähdä vahvoja yhtäläisyyksiä Friedrich Nietzschen ja Martin Heideggerin filosofioihin (ks. erityisesti, Honig 1993, Villa 1996, Kristeva 1999$)^{7}$. Juuri moderni maailma mahdollistaa uudenlaisen kriittisen suhtautumisen historiaan ja Arendtin ajattelusta löytyvä määritelmä politiikasta on nimenomaan yritys suodattaa elementtejä länsimaisesta ajatteluhistoriasta ilman nostalgista suhtautumista menneisyyteen.

Arendtin mukaan politiikka ei voi koskaan olla pelkkää yksityisten halujen toteuttamista, vaan se sijoittuu ihmisten väliseen ja jakamaan tilaan - maailmaan - jossa ihmiset voivat toimia yhdessä, yhteisen päämäärän ajamina. Poliittinen toiminta (action) perustuu inhimilliselle moneudelle (human plurality), eli sille elämän perusehdolle (Grundbedingung), että maailma koostuu monista ihmisistä, eikä yhdestä ihmisestä (vrt. Arendt 1978a, 19; Arendt 1989, 7-8; Arendt 2010, 9-12; Arendt 2015, 17). Arendtille politiikassa on kyse ainutkertaisten yksilöiden yhdessä- ja kanssaolemisesta, jota ei voida perustella millään inhimillisellä "substanssilla" (Arendt 1989, 7-8; Arendt 2010, 9-12). Juuri tästä näkökulmasta Arendt kritisoi esimerkiksi
Aristoteleen näkemystä ihmisestä "poliittisena eläimenä” (zoon politikon) ${ }^{8}$ :

Aivan kuin ihmisessä olisi jotain poliittista, joka kuuluisi hänen luontoonsa (Essenz). Juuri tämä ei pidä paikkaansa; ihminen on a-poliittinen. Politiikkaa syntyy inhimillisessä välitilassa (in dem Zwischen-den-Menschen), eli täysin ihmisen ulkopuolella. Ei ole olemassa mitään poliittista substanssia. Politiikka syntyy välitilassa ja rakentuu suhteena (Bezug). (Arendt 2010, 11.)

Politiikan tavoin myös kulttuuri sijoittuu ihmisten jakamaan maailmaan ja on siten läheisessä suhteessa politiikkaan. Kuten kulttuuri, myös politiikka on Arendtin mukaan ennen kaikkea epäluonnollista ja keinotekoista. Kulttuurillisen esinemaailman perustalla oleva inhimillinen kyky valmistaa asioita eroaa kuitenkin ratkaisevasti myös poliittisesta toiminnasta. Ajattelussaan Arendt erottaa poliittisen toiminnan (action) käsitteellisesti työstä (labor) ja valmistamisesta (work). Poliitikka vaatii paitsi vapaa-aikaa työstä - jolla Arendt viittaa elämän biologisten prosessien ylläpitämiseen - myös keinotekoisen, ihmisen itsensä valmistaman esinemaailman ja ihmisten jakaman suhteiden verkon, jonka kulttuurisessa ja kielellisessä merkityskentässä ihminen aina välttämättä toimii. Ihmisen valmistama keinotekoinen maailma mahdollistaa Arendtin mukaan politiikalle tarpeellisen näyttäytymisalueen (space of appearance) syntymisen. (Arendt 1989, 7-11, 199-207.) Koska politiikka on nimenomaan "luonnontonta" on sitä Arendtin mukaan ollut olemassa vain harvoin:

Historiallisesti puhuen on [todellista] poliittista (das Politische) ollut olemassa vain harvoina aikakausina ja vain harvat aikakaudet ovat tunteneet sen. Tästä huolimatta juuri nämä harvat suuret historian onnenkantamoiset (Glücksfälle) ovat ratkaisevia; vain niissä näyttäytyy politiikan (die Politik) merkitys (Sinn) samoin kuin politttisen (das Politische) hyvät ja huonot puolet kokonaisuudessaan (Arendt, 2010, 41-42). 
On myös syytä korostaa, että edellä pääpiirteissään esitetty kulttuuripoliittinen narratiivi julkisen alueen kuolemasta modernina aikakautena, joka löytyy Arendtin pääteoksesta ja sitä seuraavista julkaisuista, on vain yksi kertomus monien joukossa'. Tässä mielessä Seyla Benhabib (2003, xl) onkin oikeassa todetessaan, että "moderniteetti ei ollut Hannah Arendtille saumaton historiallisen kehityksen jatkumo, vaan ristiriitojen monimuotoisuuden kuvaama prosessi". Toisin kuin Kateb, joka yksinkertaisesti syyttää Arendtia radikaalista antimodernismista, Benhabib esittää huolitellumman tulkinnan ja katsoo, että Arendtin varhainen, 1930-luvulla kirjoittama, Rahel Varnhagenia käsittelevä elämäkerta $R a$ hel Varnhagen: Geschichte einer Jüdin aus der deutschen Romantik (1959) tarjoaa hyvin erilaisen kuvan modernin kulttuurin synnystä kuin Arendtin myöhemmät teokset. Teos tarkastelee juutalaisen salonginpitäjänaisen Rahel Varnhagenin elämää ja yhteiskunnallista asemaa Saksan romantiikan aikakaudella ja Benhabibin mukaan tässä "vaihtoehtoisessa modernin genealogiassa" sosiaalisen nousu näyttäytyy nimenomaan positiivisessa valossa ja välttämättömänä ennakkoehtona "uudenlaisille sosiaalisuuden muodoille, assosiaatiolle, intimiteetille, ystävyydelle, puhumis- ja kirjoitustavoille, ruokamieltymyksille, käytöstavoille ja taiteille, kuin myös harrastuksille, viihdykkeille ja vapaa-ajan aktiviteeteille" (Benhabib 2003, xii, 22).

Tämä on osuva kuvaus siitä huolimatta, että Benhabibin tapa ymmärtää Arendt "vastahakoiseksi modernistiksi" on ongelmallinen, koska se perustuu sille oletukselle, että suhteessa Arendtin myöhempään tuotantoon, hänen varhaiset teoksensa - ja etenkin Varnhagenia tarkasteleva elämäkerta - tarjoavat vaihtoehtoisen näkökulman moderniin maailmaan. Mielestäni on johdonmukaisempaa lukea Arendtin 1950-luvulla ja sen jälkeen kirjoitettuja teoksia olennaisesti nietzscheläisinä, kuin pitää Arendtia perustavan ristiriitaisena ajattelijana, joka myöhemmin vain vajoaa antimodernistiseen argumentaatioon $^{10}$. Toisin kuin Benhabib (2003, xxxix) esittää, Arendtin pääteosta The Human Condition ei voida siirtää pois tulkinnan keskiöstä, jotta Arendtin ymmärrys modernin maailman monimuotoisuudesta voisi paljastua kokonaisuudessaan, vaan Arendtin pääteosta ja muita kypsiä teoksia on nimenomaan tulkittava yrityksenä ymmärtää politiikkaa uudella tavalla, joka voisi mahdollistua 1900-luvun kontekstissa.

Vasta kirjoitettuaan teoksensa The Origins of Totalitarianism alkaa Arendt tutkia 1950-luvun alussa länsimaista kulttuuritraditiota laajemmassa merkityksessä ${ }^{11}$. Juuri totalitarismin nousu osoittaa Arendtille, että itse länsimaisessa kulttuuri- ja ajattelutraditiossa on jotain perustavan ongelmallista ja tämä saa Arendtin palaamaan antiikin maailmaan - länsimaisen sivilisaation syntysijoille ${ }^{12}$. Siirryn seuraavassa tutkimaan mitä Arendt tarkoittaa länsimaisella kulttuuritraditiolla sekä tarkastelemaan yksityiskohtaisemmin, mistä näkökulmasta poliitiikka ja kulttuuri saavat merkityksensä modernissa maailmassa. Toisin kuin Arendtia koskevassa tutkimuskirjallisuudessa on usein esitetty, argumentoin, että Arendtin paluuta antiikkiin ei voida ymmärtää missään yksinkertaisessa mielessä nostalgisena tai antimodernistisena projektina.

\section{Länsimaisen kulttuuriperinnön sirpalaisuus ja metafysiikan loppu}

Länsimainen kulttuuritraditio syntyy Arendtin mukaan antiikin Roomassa, alkaa hajota hitaasti uudella ajalla ja tulee päätökseensä 1900-luvulla. Kulttuurin käsite juontuu latinan kielen termistä colere, joka tarkoittaa vaalimista, ylläpitämistä, hoitamista ja säilyttämistä (Arendt 2006a, 208-211). Sanana myös humanismi tulee latinan kielestä (lat. humanitas) ja viittaa alunperin kirjallisuuden ja taiteen opiskelun keskeisyyteen kasvattavina tekijöinä (Arendt 2006a, 221, 290 alav. 17). Kummatkin termit, jotka olivat vieraita kreikkalaiselle antiikille, kielivät siitä, että juuri Roomassa syntyy uudenlainen ajatus kulttuurin itseisarvosta, sen vaalimisesta ja säilyttämisestä jälkipolville. Roomalaiset luovat Arendtin mukaan perustan länsimaiselle sivilisaatiolle sekä poliittisessa että laajemmassa kulttuurillisessa mielessä. 
Uudenlainen tapa ymmärtää historiaa näkyy siinä, että Rooman kaupungin perustaminen ymmärretään alusta alkaen ainutkertaisena historiallisena tapahtumana ja uuden aikakauden alkuna. Toisin kuin Kreikan kaupunkivaltioiden siirtokunnat, jotka säätivät omat lakinsa eivätkä olleet suoranaisesti riippuvaisia mistään muusta poliksesta, olivat Rooman siirtokunnat alusta saakka roomalaisen lain alaisia ja kuuluivat samaan poliittiseen yhteisöön. (Arendt 2005, 49.) Ajatus Rooman perustamisen ainutkertaisuudesta yhdistää Arendtin mukaan poliittisen toiminnan ja uskonnon toisiinsa. Roomalainen "uskonto oli se voima, joka turvasi [Rooman] perustamisen tarjoamalla jumalille asuinpaikan ihmisten parissa,..., se otti pyhäksi tehtäväkseen säilyttää kaiken esi-isiltä - meitä itseämme suuremmilta (maiores) - perityn" (Arendt 2005, 49). Roomassa kreikkalainen kulttuurimenneisyys ymmärretään ensimmäistä kertaa menneisyytenä, jolla on auktoriteetti (lat. auctoritas), eli traditiona. Roomalainen sivilisaatio yhdistää uskonnon, auktoriteetin ja tradition toisiinsa palauttamalla nämä kaikki itse Rooman perustamisen ainutkertaiseen tapahtumaan. (Arendt 2005, 49-50.) Arendt selventää mainittujen käsitteiden suhteita toisiinsa seuraavasti:

Menneisyydellä on auktoriteetti siinä määrin kuin se siirtyy eteenpäin traditiona; auktoriteetti, siinä määrin kuin se esittää itsensä historiana, muuttuu traditioksi; ja jos auktoriteetti ei Platonin hengessä julista, että ,jumala (eikä ihminen) on kaiken mitta, "se on vain sattumanvaraista tyranniaa, eikä auktoriteettia. (Arendt 2005, 73).

Arendt korostaa, että kreikkalaisen sivilisaation nostaminen auktoriteetin asemaan koski ennen kaikkea kreikkalaista filosofiaa, jonka hän ymmärtää myös kreikkalaisen sivilisaation keskeisimpänä kontribuutiona länsimaiselle kulttuurihistorialle (Arendt 2005, 54). Länsimaisen ajattelun ja metafysiikan perusteet syntyvät antiikin filosofien parissa, etenkin Platonin ja Aristoteleen filosofioissa. Sokrateen kuolemantuomio Ateenan demokraattisessa kaupunkivaltiossa on Arendtin mukaan se ratkaiseva tapahtuma, joka osoitti filosofeille, että politiikka on filosofian näkökulmasta äärimmäisen vaarallis- ta. Sokrateen kuolemantuomion myötä filosofit alkavat nähdä poliittisen toiminnan ja poliittisen elämänmuodon (bios politikos) pelkkänä välineenä, jonka tehtävä oli palvella korkampaa, filosofista elämäntapaa (bios theoretikos). (vrt. Arendt 1989, 12-21; Arendt 1994a, 428-429; Arendt 2005, 5-8; Arendt 2006a, 156; Arendt 2012, 46-47.) Yhtäältä kreikkalaisen filosofian korkea arvostus esti roomalaisia kehittelemästä omaa poliittista filosofiaansa ja artikuloimasta käsitteellisessä muodossa omaa kokemustaan poliittisen merkityksestä. Toisaalta juuri kreikkalaisten filosofien näkemys politiikan välineellisestä olemuksesta periytyy Rooman välityksen myötä keskelle kristillistä dogmatiikkaa. Myöhemmin Roomassa tradition auktoriteettia vaali kristinusko, joka nousi Konstantinuksen myötä perinteisen roomalaisen uskonnon rinnalle ja myöhemmin ainoaksi sallituksi uskonnoksi. (Arendt 2005, 50, 54.)

Traditiolla Arendt ei tietenkään tarkoita kaikkia mahdollisia filosofioita tai poliittisia teorioita, vaan nimenomaan niitä standardeja, joilla jokin teoria, näkemys tai kokemus hyväksyttiin validiksi, eli kanonisoitiin. Kaikkia traditioita luonnehtii taipumus hylätä sellaiset kokemukset ja ajatukset, jotka eivät olleet johdonmukaisia sen perustavien standardien kanssa. (Arendt 2005, 47; Arendt 2006a, 93.) Tradition, auktoriteetin ja uskonnon kolminaisuus säilyy Arendtin mukaan ehjänä kristillisen perinteen välityksellä aina uudelle ajalle saakka, jolloin traditio ja sen metafysiikka alkavat pikku hiljaa menettää uskottavuuttaan ilmiöiden ja olemisen selittäjänä (Arendt 2005, 40-62). Kyseessä on kulttuurihistoriallinen narratiivi, sillä Arendt katsoo nimenomaan antiikin filosofian tarjonneen ne perustavat standardit, joilla myös kulttuuria ja ihmisen paikkaa siinä on ymmärretty.

Vaikka Arendt (2006a, 234) korostaa, että jokaisella sukupolvella on oikeus kirjoittaa oma historiansa, eli järjestää historialliset faktat omasta perspektiivistään, on hänen mukaansa toisen maailmansodan jälkeinen perspektiivi kuitenkin tietyssä mielessä ainutlaatuinen. Arendtin ajattelun läpäisee näkemys siitä, että länsimainen ajattelu- ja kulttuuritraditio katkeavat lopullisesti juuri 1900-luvulla. Totalitaa- 
rinen hallinta ja holokausti ennennäkemättöminä tapahtumina kyseenalaistavat perimmäiset oletuksemme ihmisluonnosta, politiikasta ja kulttuurista - nämä tapahtumat katkaisevat länsimaisen kulttuuri- ja ajattelutradition luoden "kuilun menneisyyden ja tulevaisuuden välille" (a gap between past and future). (vrt. Arendt 1994a, ix, 459-460; Arendt 1994b, 158-159, 309-310, 405; Arendt 2006a, 3-15, 26.)

Arendt näkee tradition katkeamisen myös vapauttavana ilmiönä ja etenkin viimeisessä teoksessaan The Life of the Mind (1978) tämä historiallinen kehitys esitetään positiivisessa valossa. Ajatus länsimaisen tradition päättymisestä on Arendtin mukaan 1900-luvun fenomenologisen tradition, Husserlin ja Heideggerin ajattelun keskeisimpiä tausta-oletuksia (Arendt 1978a, 9). Myös jo varhaisemmat Hegelin ja Nietzschen huomautukset "jumalan kuolemasta" viittaavat siihen, että traditionaalinen tapamme ajatella sekä jumalaa - absoluuttista transendenssia - että kysyä ajattelutraditiolle ominaisia metafyysisiä kysymyksiä on menettänyt uskottavuutensa (Arendt 1978a, 9-10). Arendt spekuloi tämän "metafysiikan lopun" tuomia etuja seuraavin sanoin:

[Historiallisen] tilanteemme etulyöntiasema, joka seuraa metafysiikan ja filosofian hajoamista (demise) olisi kaksinainen. Se sallisi meidän katsoa menneisyyteen uusin silmin, ilman minkään tradition ohjausta tai taakkaa ja siten antaisi käyttöömme raakojen kokemusten valtavan runsauden ilman, että olisimme minkään määräysten sitomia sen suhteen, kuinka näihin aarteisiin suhtautuisimme. (Arendt 1978, 12.)

Tätä Arendtin tradition katkeamisen positiivista aspektia ei tule kuitenkaan rajoittaa yksinomaan hänen viimeiseen teokseensa. Arendt lainasi usein ${ }^{13}$ ranskalaisen kirjailijan Réné Charin mietelausetta "perintömme on jätetty meille ilman testamenttiä" (notre héritage n'est précédé d'aucun testament) kuvatakseen sitä historiallista tilannetta, jossa länsimaisen "tradition lanka on katkennut ja meidän täytyy itse löytää menneisyytemme - toisin sanoen, meidän tulee lukea sen kirjoittajia aivan kuin kukaan ei oli- si koskaan lukenut heitä aikaisemmin" (Arendt 2006, 201). Modernin maailman näkökulmasta länsimainen kulttuurihistoria näyttäytyy Arendtin mukaan "sirpaleisena menneisyytenä" (fragmented past):

Historiallisesti puhuen, se mikä itse asiassa on luhistunut on roomalainen kolminaisuus, joka tuhansien vuosien ajan yhdisti uskonnon, auktoriteetin ja perinteen,..., se mikä on menetetty on menneisyyden jatkumo, siten kun se siirtyi sukupolvelta sukupolvelle,..., siten se mikä on jäänyt jäljelle on yhä menneisyys, mutta sirpalainen menneisyys (Arendt 1978a, 212).

Kuten on usein korostettu (ks. esim. Taminiaux 1992, Ettinger 1995, Villa 1996, Kristeva 1999, Wolin 2001, Benhabib 2003, Grunenberg 2006) Arendtin ajattelussa voidaan nähdä vahvoja yhteyksiä Martin Heideggerin filosofiaan. Yhtäältä Arendtin analyysi länsimaisen tradition roomalaisesta alusta ja metafysiikan Kreikassa syntyvästä perusluonteesta heijastelee vahvasti Heideggerin narratiivia länsimaisesta historiasta. Toisaalta juuri Heideggerin tunnettu kritiikki modernia, Descartesista alkavaa subjektifilosofiaa kohtaan on myös keskeisessä roolissa Arendtin ajattelussa. Kuten Dana Villa (1996, 12-13) korostaa, sekä Arendt että Heidegger pyrkivät ajattelemaan inhimillisen olemisen perusteita tavalla, joka ylittää länsimaisen perinteen ongelmallisimmat oletukset: Molemmille ajattelijoille juuri modernissa maailmassa nousee mahdollisuus ymmärtää itse metafysiikan perusteita uudella tavalla, ilman tradition ohjaavaa auktoriteettia.

Niin Arendtin kulttuurifilosofinen ja poliittinen aikalaisdiagnoosi kuin myös hänen näkemyksensä modernin ajan aiheuttamasta katkoksesta tässä perinteestä voidaan johtaa takaisin Heideggerin keskeisimpiin ajatuskulkuihin. Sekä Arendt että Heidegger korostavat Descartesin roolia modernin ihmisymmärryksen ja subjektifilosofian keskeisenä alullepanijana. (vrt. Arendt 1989, 273-274; Heidegger 2000, 35; Heidegger 2015, 99.) Esseessään Maailmankuvan aika (1938) Heidegger nimeää viisi uudelle ajalle tyypillistä ilmiötä: Modernin tieteen syntymisen, konetekniikan kehittymisen, tai- 
teen siirtymisen estetiikan piiriin, uudenlaisen ymmärryksen inhimillisestä toiminnasta kulttuurina sekä jumalien katoamisen (Entgötterung) (Heidegger 2000a, 9-10; Heidegger 2015, 75-76). Heideggerille modernin aikakauden keskeinen merkki on, että maailmaa aletaan havainnoida ymmärtää tiettynä objektiivisena asiatilana - "maailmankuvana" (Weltbild) (Heidegger 2000, 25; Heidegger 2015, 88-89). Myös Arendt (1978; 1989) korostaa valmistamisen (work) täysin uudenlaista arvottamista uuden ajan myötä sekä jumalten kuoleman merkitystä modernille maailmalla. Alluusiona Heideggerin ajatteluun Arendt toteaakin:

Olen selkeästi liittynyt niiden joukkoon, jotka ovat jo jonkin aikaa yrittäneet purkaa (dismantle) metafysiikkaa ja filosofiaa keskeisinä kategorioineen, siten kuin me olemme ne tunteneet aina niiden alusta Kreikassa nykyaikaan saakka. Tällainen purkaminen on mahdollista vain sillä oletuksella, että tradition lanka on katkennut emmekä voi korjata sitä. (Arendt 1978a, 212.)

Arendt $(2012 b, 48)$ itse esitti, että hänen ajattelunsa keskeinen tavoite tai päämäärä oli "tarve ymmärtää". Hänen yrityksensä ymmärtää politiikan ja kulttuurin merkitystä 1900-luvun kontekstissa tapahtui alusta saakka filosofien, kirjailijoiden ja runoilijoiden silmin. Kuten Seyla Benhabib (2003, 91-92) korostaa, Arendtin historiallisia narratiiveja yhdistää nimenomaan yritys tehdä länsimaisen kulttuuritradition "sirpaleisesta menneisyydestä” merkityksellinen nykymaailman näkökulmasta, minkä taustalla on oletus siitä ettei menneisyyttä enää voida kertoa yhtenäisen tradition muodossa ${ }^{14}$. Arendtin näkemys länsimaisen kulttuuritradition katkeamisesta antaa keskeisen roolin nimenomaan menneisyyden kerronnalle, narrativiteetille $^{15}$ : menneisyyden sirpaleisuus vapauttaa meidät tradition kahleista ja mahdollistaa perinteen kertomisen uudella tavalla. Siirryn seuraavassa tutkimaan, millainen merkitys kertomuksellisuudella on Arendtin ajattelussa, sekä pohtimaan, missä mielessä filosofialla ja taideteoksilla on erityinen narratiivinen ja historiallis-metaforinen voima.

\section{Taiteen ja filosofian narratiivinen ja metaforinen voima}

Arendt lainaa useissa teoksissaan kirjallisia kuvauksia historiasta. Esimerkiksi Franz Kafkan teoksesta Linna (1926) Arendt löytää kuvauksen moderin valtion kasvottomasta byrokratiasta ja juutalaisten epäonnistuneesta yrityksestä assimiloitua heille vihamielisiin eurooppalaisiin yhteiskuntiin. Hermann Brochin klassikkoteosta Der Tod des Vergil (1945) Arendt lukee ikään kuin metaforana länsimaisen tradition päättymisestä ${ }^{16}$. Myös totalitarismin alkuperää tutkivassa teoksessaan Arendt nojaa laajalti kirjallisuuteen. Kuvatessaan ekskluusion ja inkluusion mekanismeja sosiaalisen alueen nousun aikakaudella Arendt vetoaa Marcel Proustin klassikkoon Kadonnutta aikaa etsimässä (19131927) ${ }^{17}$. Kuvatakseen imperialistien kokemusta Afrikan valloituksesta Arendt referoi Joseph Conradin teosta Pimeyden Sydän $(1899)^{18}$. Myös kuvatakseen keskitysleirien olemusta joissa moderni nihilistinen prinsiippi "kaikki on sallittua" korvautuu paljon radikaalimmalla ja ennennäkemättömällä periaatteella, jonka mukaan "kaikki on mahdollista" - Arendt vetoaa David Rousset'n teokseen Les jours de notre mort $(1947)^{19}$.

Yhdysvaltain ja Ranskan vallankumouksia analysoivassa teoksessa On Revolution Arendt käyttää sekä Herman Melvillen teosta Billy Budd (1924) että Dostojevskin klassikkoa Karamazovin veljekset (1880) analysoidakseen hyvyyden, myötätunnon ja säälin ongelmallista roolia politiikassa ja etenkin Ranskan vallankumouksessa $^{20}$. Lisäksi Arendt vetoaa kirjallisuuteen myös havainnollistaakseen teoksessaan Eichmann in Jerusalem: A Report on the Banality of Evil (1963) esittelemäänsä kuuluisaa banaalin pahan käsitettään. Eichmann on Arendtin mukaan täysin uudenlainen rikollinen, jolta puuttuu Shakespearin, Melvillen tai Dostojevskin kirjallisten hahmojen "radikaali pahuus"21, joka on nimensä mukaisesti juuriin (lat. radix) asti menevää ja perustuu epätoivolle ja kateudelle. (Arendt 2003, 74; vrt. Arendt 2012b, 131) Eichmann oli Arendtin mukaan sen sijaan rikollinen, joka nautti puhtaasta funktionaali- 
suudesta ja oli kyvytön kuvittelemaan tekojensa seuraksia (Louise-Knott 2015, 4,7).

Miksi Arendt nojaa näin laajasti nimeomaan taiteellisiin ja fiktionaalisiin teoksiin poliittista historiaa ja politiikan teoriaa käsittelevissä teoksissaan? Kuinka Arendt itse ymmärtää taiteen historian kuvaajana? Onko taiteella Arendtin mukaan erityinen asema historian valaisijana?

Taiteen maailmallista luonnetta, inhimillistä merkityksellisyyttä ja sen eri muotoja Arendt pohtii poliittiselle ajattelulleen keskeisten käsitteiden kautta kaikkein kattavimmin teoksessaan The Human Condition. Teoksen perustava käsitteellinen kolmijako työn, valmistamisen ja toiminnan välille luo pohjan myös Arendtin taideanalyysille. Taideteokset ovat Arendtin mukaan mukaan luontoonsa kuuluvan kestävytensä vuoksi kaikista ihmisen valmistamista asioista juuri maailmallisimpia. Taiteella ei ole sinänsä mitään yksiselitteistä päämäärää, arvoa tai hyödyllistä funktiota maailmassa. (Arendt 1989, 167-168; Arendt 2015, 201-202.) Nimenomainen kriteeri, jolla taideteoksia tulee arvostella on niiden estettisyys - kauneus tai rumuus - joka on kaiken funktionaalisuuden tai utilitariteetin tuolla puolen (Arendt 2015, 210). Taideteoksissa maailmallinen pysyvyys ja kontinuiteetti tulee läpinäkyväksi, koska ne ikään kuin paljastavat inhimillisen kyvyn tavoitella kuolemattomuutta omien tekojensa kautta (Arendt 1989, 168; Arendt 2015, 202). Kestävyytensä ansiosta taideteokset tuovat selkeästi esille inhimillisen kyvyn valmistaa esineitä. $\mathrm{Ne}$ muistuttavat meitä siitä, että niin asioiden fyysinen kestävyys, kuin myös inhimillisten kokemusten järjestyminen tarinoiksi jossain jaetussa maailmassa tai kollektiivisessa muistissa on itse inhimillisen historian ennakkoehto (Arendt 2015, 212).

Vaikka taideteokset perustuvat inhimilliseen kykyyn ajatella (denken) ja pohtia (sinnen) - siis sinällään sellaisiin kykyihin, jotka eivät ilmene maailmassa toisille - tulee niistä valmistusprosessin kautta myös konkreettisia asioita asioiden joukossa. Inhimillisenä kykynä ajattelu ei itsessään jätä jälkeensä mitään kouriintuntuvaa ja siten taideteosten valmistaminen on samalla ajatusten tai ideoiden muuttamista objekteiksi (Verdinglichung). Tämä pitää Arendtin mukaan paikkansa yhtä hyvin runouden ja kirjallisuuden, musiikin, maalaustaiteen kuin kuvanveistonkin suhteen. (Arendt 2015, 203-204.) Arendt seuraa Immanuel Kantin tapaa erottaa järki (Vernunft) ja ymmärrys (Verstand) toisistaan korostaessaan, että filosofian ja taiteen alkuperäisenä lähteenä on nimenomaan ajattelu, jolla ei sinällään koskaan ole mitään yksittäistä päämäärää, kun taas tiede toimii ikään kuin havainnointi- ja ymmärryskykymme jatkeena ja asettaa itsellään konkreettisia päämääriä. Sekä filosofi että taitelija joutuvat muuttamaan ajattelemansa ja keskeyttämään itse ajattelun, mikäli he haluavat saada ajatuksensa esille valmistaen, esimerkiksi kirjoittaen, säveltäen tai veistäen. (vrt. Arendt 1978a, 13-16, 60-61; Arendt 1989, 170-174; Arendt 2015, 206-212.)

Taiteen ja kulttuurin erityinen luonne ja inhimillisyys onkin juuri niiden kaksinaisessa luonteessa. Yhtäältä taiteen pohja ja perusta on inhimillisessä ajattelukyvyssä, jonka lopputulokset säilyvät meille vain jos ne alistetaan päämäärähakuiselle valmistamiselle ja muutetaan konkreettisiksi esineiksi. Toisaalta objekteiksi muutetut taideteokset eivät itsessään Arendtin mukaan ole funktionaalisia, vaan ne ovat perustavassa hyödyttämyydessään ja poikkeuksellisessa fyysisessä kestävyydessään asioista maailmallisimpia, vain julkisessa tilassa merkityksensä saavia objekteja. Arendtin $(2015,205)$ mukaan taidemuodoista maailmattomimpia ja vähiten konkreettisia ovat musiikki ja runous, sillä niiden materiaalit - äänet ja sanat - ovat vain epäsuorasti yhteydessä itse valmistettavaan taideteokseen. Juuri runous tai sanataide (Dichtkunst) on Arendtin mukaan taidemuodoista kaikkein "inhimillisin" (menschlischte), koska sen materiaali on kieli itse, joka on kaikista mahdollisista materiaaleista inhimillistä ajattelua lähimpänä. (Arendt 2015, 205.) Taidemuodoista poliittisin on puolestaan teatteri, sillä vain teatterissa inhimillisten yksilöiden välitön suhde muuttuu taiteeksi (Arendt 1989, 188).

Arendtille länsimaisen tradition katkeaminen ja metafysiikan loppu ovat myös siinä merkityksessä positiivisia asioita, että ne mahdollistavat oman historiamme tutkimisen merkityshistoriana, jota sekä filosofiset käsitteet että taideteokset ilmentävät erityisen intensiivisesti. 
Tradition auktoriteetin hajoaminen mahdollistaa menneisyyteen katsomisen uusin silmin. Kuten Heideggerille, myös Arendtille historiassa on keskeistä tutkia nimenomaan "olemisen merkitystä" (Sinn von Sein) ${ }^{22}$. Tätä lähestymistapaa voidaan kutsua myös hermeneuttiseksi: Käsitteet avaavat ja heijastavat erilaisia ja muuttuvia tapojamme jäsentää omaa kokemustamme todellisuudesta ja siksi niiden historiallinen kontekstualisointi ja analyysi mahdollistaa nykypäivän näkökulmasta erilaisten olemis- tai todellisuusymmärrysten hahmottelemisen. Se, että kreikkalaisilta puuttuivat esimerkiksi jo mainitut kulttuurin, humanismin ja auktoriteetin käsitteet siinä merkityksessä, jossa roomalaiset näitä käyttivät, ilmentää Arendtille perustavaa muutosta tavassa ymmärtää itse inhimillistä olemista. Tässä mielessä Arendt kirjoittaa:

Kaikki filosofiset termit ovat metaforia, ikään kuin jäätyneitä analogioita. Niiden todellinen merkitys paljastuu kun ne liuotetaan (dissolve) niiden alkuperäiseen kontekstiin, jonka on täytynyt olla elävästi sen filosofin mielessä, joka käytti termiä ensimmäistä kertaa. (Arendt 1978a. 104.)

Arendt antaa esimerkkeinä tälläisista termeistä Platonin käsitteet sielulle (psyche) ja idealle (eidos) sekä Aristoteleen tavan käyttää termejä energos (liike, aktualiteetti) ja kategoria (Arendt 1978a, 103-104). Kaikki filosofiset termit ovat Arendtille metaforia siksi, että niiden pohjalla on tietty kokemus, jonka inhimillinen järki abstrahoi esimerkiksi havaitusta todellisuudesta. (Arendt 1978a, 102-105). Arendt käyttää termiä metafora sen kreikkalaisessa merkityksessä metapherein: siirtää, muuttaa, tuoda ylitse, tuoda toiselle puolen. Kielen kuvallinen käyttö mahdollistaa aistikokemuksien ja järjen spekulaatioiden tuomisen ajattelun ja kielen tasolle, niiden tuomisen ikään kuin "toiselle puolelle“ (carrying-over). (Arendt 1978a, 110). Metaforan alkuperä onkin Arendtin mukaan runollinen Arendt myös korostaa jatkuvasti runouden ja filosofian olemuksellista läheisyyttä toisiinsa ${ }^{23}$ - ja sen varsinainen keksijä, Arendt jatkaa, länsimaiden varhaisin tunnettu eeppinen runoilija, Homeros (Arendt 1978a, 105-106).
Sekä filosofia että taide ovat Arendtille historian peilejä, joilla on perustavan metaforinen tai kuvallinen luonne. Niin taideteokset kuin filosofiset käsitteetkin ilmaisevat tiettyä tapaa hahmottaa itse kokemustamme todellisuudesta: Taiteessa ja filosofiassa „ajattelevan minän kokemus siirtyy asioihin itseensä“" (Arendt 1978a, 185). Juuri taiteilija on Arendtille niiden esineiden autenttinen valmistaja, jotka jokainen sivilisaatio jättää jälkeensä aivan kuin todistuksena "sen hengen olemuksesta, joka innoitti sitä" (Arendt 2006a, 197). Myös Arendtin harjoittama hermeneuttinen käsiteanalyysi on välttämättä kertomista, narraatiota, kielellistä analyysiä. Kaikki maailmallinen ja inhimillinen merkityksellisyys perustuu Arendtin mukaan pelkkien historiallisten ja faktuaalisten totuuksien yläpuolelle nousemiseen kielen ja kertomusten avulla. Arendt antaa runoilijoille ja historioitsijoille tehtäväksi juuri tällaisen kertomisen alkuun saattamisen:

Siinä määrin kuin menneisyys ylipäätään voidaan voittaa (Bewältigen), perustuu voittaminen menneisyyden jälkeen päin kertomiselle (Nacherzählen): Mutta myöskään tämä jälkeen päin kertominen, joka muodostaa historian, ei ratkaise mitään ongelmia tai rauhoita mitään tuskaa - se ei voita (bewältigt) mitään lopullisesti. Niin kauan kuin tapahtuneen merkitys pysyy eläväisenä - ja tämä voi olla asian laita hyvinkin pitkien ajanjaksojen ajan - liikuttaa tämä meitä kohti jatkuvasti toistuvaa uudelleen kertomista. Runoilijoilla on hyvin yleisessä ja historioitsijoilla hyvin erityisessä mielessä tehtävä saatta tämä kertominen alkuun ja johdattaa meidät siihen,..., niin runoilijan kuin myös historioitsijan objektifikaatiossa (Verdinglichung) löytää historiankertomus sen vakauden ja pysyvyyden, joka mahdollistaa kertomuksen järjestämisen (einordnen) maailmaan, jossa se voi säilyä tarinana tarinoiden joukossa. (Arendt 2012, 33-34.)

Kuvatakseen kertomuksellisuuden perustavaa merkitystä ihmiselämälle, Arendt lainasi usein Isak Dinesenin (Karen Blixen) toteamusta, "kaikki surut voidaan kestää, jos ne asetataan osaksi tarinaan tai jos niistä kerrotaan tarina" (Arendt 1989, 175; Arendt 2006a, 257). Tähän 
Dinesen olisi Arendtin mukaan voinut lisätä, että "myös ilo ja onni tulevat siedettäviksi ja merkityksellisiksi ihmisille ainostaan silloin kun he voivat puhua niistä ja kertoa ne tarinana" (Arendt 2006a, 257). Arendtin mukaan juuri tarinoiden kertominen on inhimillisen elämän keskeisin piirre, joka tekee elämästämme (bios) enemmän kuin ainostaan "luonnollista" (zoe) (Arendt 1989, 97).

Näiden pohdintojen taustalla on oletus siitä, että metafysiikan loppu vapauttaa meidät ajattelemaan inhimillistä olemista ja sille keskeistä kertomuksellisuutta uudella tavalla. Tradition katkeaminen valaisee myös estettisen arvostelukyvyn ja politiikan olemuksellista läheisyyttä. Arendt näki tunnetusti Immanuel Kantin esteettistä arvostelukykyä käsittelevässä teoksessa Kritik der Urteilskraft (1790) hänen "kirjoittamattoman" ja "todellisen" poliittisen filosofiansa. (vrt. Arendt \& Jaspers 1985, 355; Arendt 1992, 19). Tradition tarjoamien standardien katoaminen vapauttaa Arendtin mukaan poliittisen arvostelukyvyn (judgement) ymmärtämisen "kykynä tuomita partikulaareja alistamatta niitä yleisten sääntöjen alaisuuteen" (Arendt 2003, 188-189; vrt. Arendt 2005, 104). Arendt vetoaa juuri Kantin kolmanteen kritiikkiin pyrkiessään osoittamaan esteettisten arvostelmien poliittisuuden: "on aivan kuin arvostelukyky ei ainostaan päättäisi siitä miltä maailman tulee näyttää, vaan myös siitä, ketkä siihen kuuluvat" (Arendt 2006a, 220). Arvostelukyky on Arendtin mukaan "poliittinen kyky, joka todella humanisoi kauniin ja luo kulttuurin" (Arendt 2006a. 221) ${ }^{24}$.

Taideteokset ja filosofia ovat Arendtille historiallisesta näkökulmasta merkityksellisiä siksi, että ne heijastavat ja paljastavat aiempien aikojen tapoja ajatella: Heideggerin termein, ne heijastelevat aiempien aikakausien "olemisymmärrystä" (Seinsverständnis). Arendtille taide valaisee historiaa nimenomaan ei-totalisoivana merkityshistoriana. Menneisyyden merkitys voi olla vain siinä, että se kerrotaan menneisyytenä yhä uudelleen lukemattomista eri näkökulmista $^{25}$. Juuri tässä mielessä Arendt (2012a, 198) itse väitti, että Walter Benjaminin ajattelua määrittelee hänen tapansa "ajatella runollisesti" (dichterisch Denken), kaikkiin perinteisiin ja traditioihin kriittisesti suhtautuen. Myös Aren- dtin narratiivit ja kertomukset länsimaisesta historiasta ovat esimerkkejä runollisesta ajattelusta.

\section{Lopuksi}

Tutkimuksen pohjalta on tärkeää kysyä, missä mielessä Arendtia voidaan pitää ajankohtaisena kulttuuripoliittisena ajattelijana? Ovatko Arendtin tarjoamat narratiivit länsimaisesta historiasta uskottavia ja mahdollistavatko Arendtin teoreettiset käsite-erottelut luontevia työkaluja kulttuurin ja taiteen ymmärtämiseksi? Ennen kaikkea on syytä korostaa, että luonnehdinta Arendtista täysin antimodernina ajattelijana perustuu yksipuoliseen tulkintaan, joka ei tarkastele Arendtin ajattelua riittävän kokonaisvaltaisesti. Toisin kuin esimerkiksi Kateb, ja osin myös Benhabib, tuntuvat väittävän, moderniteetti ei tarkoita Arendtille filosofian loppua tai täydellistä poliittis-kulttuurillista umpikujaa, vaan historiallista tilannetta, joka pakottaa meidät suhtautumaan kriittisesti omaan ajattelu- ja kulttuuriperinteeseemme. Vaikka 1900-luku on Arendtille teollisen massakulttuuriin aikakausi, on se myös potentiaalisen emansipatorinen hetki, joka vapauttaa meidät ymmärtämään omaa kulttuurimenneisyyttämme ilman tradition kankeita suuntaviivoja. Juuri tähän viitaten Arendt (2012b, 113) itse määritteli oman ajattelunsa yrityksenä "ajatella ilman kaiteita" (Denken ohne Geländer), eli ilman länsimaisen tradition ongelmallisimpia oletuksia.

Kultturipoliittisena ajattelijana Arendt on siinä mielessä ongelmallinen teoreetikko, että hänen keskeisimmät ajatuksensa kulttuurista ja taiteesta ovat vahvasti kiinni hänen poliittisen ajattelunsa keskeisimmissä käsite-erotteluissa. Arendtille modernin länsimaisen kulttuurin kriisi ei näyttäydy ainoastaan sen poliittisen kriisin valossa, vaan myös sen varjossa. Toiseksi on myös selvää, että Arendtin ajattelusta löytyvä kertomus länsimaisen kulttuuriperinteen synnystä ja katkeamisesta on ongelmallinen. Vaikka Arendtin narratiivi länsimaisesta kulttuuritraditiosta on tarkoitettu nimenomaan tämän tradition kritiikiksi, tätä narratiivia voidaan luonnehtia eurosentriseksi, sillä Arendt ei juuri- 
kaan käsittele muiden kulttuuripiirien vaikutusta länsimaiseen ajattelutraditioon. Myös Arendtin tapa nojautua Heideggerin näkemykseen länsimaisen metafysiikan lopusta liittää Arendtin osaksi nykyfilosofian keskustelua "modernin lopusta", jonka ongelmallisuutta on laajalti korostettu etenkin "postmodernin" -käsitteen ympärille muodostuneessa keskustelussa ${ }^{26}$.

Mainituista ongelmista huolimatta Arendtin ajattelu tarjoaa omaperäisen teorian sekä taiteen merkityksestä että politiikan suhteesta kulttuu- riin. Hänen filosofis-poliittinen esseistiikkansa on edelleen lähes ainutlaatuista politiikan tutkimuksen parissa. Onkin perusteltua ajatella, että 2010-luvulla jatkuva "Arendt-renesanssi"27 laajenee myös kulttuuripoliittisen tutkimuksen alueelle ja siten vain kasvattaa Arendtin ajatuksien merkityksellisyyttä ja vaikutusvaltaa myös tulevaisuudessa.

\section{Lähdeviitteet}

Arendt, H. (1978). The Life of The Mind. 2.vols. New York: Harcourt.

Arendt, H. (1989). The Human Condition [1958]. Chicago: The University of Chicago Press, Chicago.

Arendt, H. (1992). Lectures on Kant's political Philosophy [1982]. Chicago: The University of Chicago Press.

Arendt, H. (1994a). The Origins of Totalitarianism [1951]. New York: Harcourt.

Arendt, H. (1994b). Essays in Understanding 1930-1954. New York: Schocken.

Arendt, H. (2002). "Karl Marx and the Tradition of Western Political Thought". Social Research 69 (2), 273-319.

Arendt, H. (2003a). Denktagebuch 1950-1973. 2. vols. (toim.) Nordmann, I. \& Ludz, U. München: Piper.

Arendt, H. (2003b). Responsibility and Judgement. New York: Schocken.

Arendt, H. (2005). The Promise of Politics. New York: Schocken.

Arendt, H. (2006a). Between Past and Future [1954]. New York: Penguin.

Arendt, H. (2006b). On Revolution [1963]. New York: Penguin.

Arendt, H. (2006c). Eichmann in Jerusalem: a Report on the Banality of Evil [1963]. New York: Penguin.

Arendt, H. (2007a). Reflections on Literature and Culture. Redwood: Stanford University Press.
Arendt, H. (2007b). The Jewish Writings. New York: Schocken.

Arendt, H. (2010). Was ist Politik [1993]. München: Piper.

Arendt, H. (2012a). Menschen in finsteren Zeiten [1989]. München: Piper.

Arendt, H. (2012b). Ich will Verstehen [1996]. München: Piper.

Arendt, H. (2013). Rahel Varnhagen: Lebensgeschichte einer deutschen Jüdin aus der Romantik [1959]. München: Piper.

Arendt, H. (2015a). Ich Selbst, auch Ich tanze. Die Gedichte. München: Piper.

Arendt, H. (2015b). Vita Activa oder Vom tätigen Leben (1960). München: Piper.

Arendt, H. \& Jaspers, K. (1985). Briefwechsel 1926-1969. München: Piper.

Arendt, H. \& Scholem, G. (2010). Der Briefwechsel. Frankfurt: Jüdischer Verlag.

Backmann, J. (2010). "The end of Action: An Arendtian critique of Aristoteles' concept of Praxis". Teoksessa Ojakangas, M. (toim). Hannah Arendt: Practice, Thought and Judgement (28-47). Helsinki: Studies across Disciplines in the Humanities and Social Sciences (8).

Badiou, A. (2011). Filosofian puolesta. Kaksi Manifestia [1989; 2009]. Kääntänyt Pekonen, L., Porttikivi, J., Tuomikoski, A. Tampere: Tutkijaliitto. 
Benhabib S. (2003). The Reluctant Modernism of Hannah Arendt. Usa: Rowman \& Littlefield.

Braver, G. (2011). The Problem with Reading Hannah Arendt in English. Stuttgart: VDM Verlag.

Broch, H. (1958). Der Tod des Vergil [1945]. Zürich: Rhein-Verlag.

Conrad, J. (1968). Pimeyden sydän [1899]. Kääntäny† Kivivuori, K. Helsinki: Otava.

Dostojevski, F.M. (2008). Karamazovin veljekset [1880]. Suom. Pyykkö, L. Hämeenlinna: Karisto.

Ettinger, E. (1995). Hannah Arendt-Martin Heidegger. New Haven: Yale Unversity Press.

Grunenberg, A. (2006). Hannah Arendt und Martin Heidegger: Geschichte einer Liebe. München: Pieper.

Habermas, J. (1993). Der philosophische Diskurs der Moderne: zwölf Vorlesungen [1985]. Frankfurt am Main: Suhrkamp.

Hahn, B. \& Louise-Knot. M. (toim.) (2007). Hannah Arendt: Von den Dicterhn erwarten wir Wahrheit. Berlin: Matthes \& Seitz.

Heidegger, M. (2000). "Maailmankuvan aika". Suom. Markku Lehtinen. Helsinki: Tutkijaliitto.

Heidegger, M. (2006). Sein und Zeit [1927]. Tübingen: Max Niemeyer.

Heidegger, M. (2007). Oleminen ja Aika [1927]. Kääntänyt Reijo Kupiainen.Tampere: Vastapaino.

Heidegger, M. (2015). Holzwege [1950]. Frankfurt am Main: Klostermann.

Hever, W. \& Von der Lühe, I. (toim.) (2007). Dichterisch denken - Hannah Arendt und die Künste. Göttingen: Wallstein Verlag.

Kafka, F. (1964). Linna [1926]. Kääntänyt Aarno Peromies. Helsinki: Otava.

Kalyvas, A. (2008). Democracy and the Politics of the Extraordinary: Max Weber, Carl Schmitt and Hannah Arendt. New York: Cambridge University Press.

Kant, I. (1990). Kritik der Urteilskraft [1790]. Frankfurt am Main: Suhrkamp.

Kateb, G. (1983). Hannah Arendt: Politics, Conscience, Evil. Totowa: Rowman \& Allanheld.

Kristeva, J. (1999). Le génie féminin 1. Hannah Arendt. Paris: Gallimard.

Latour, B. (2006). Emme ole koskaan olleet moderneja [1991]. Tampere: Vastapaino.

Lloyd, M. (1995). "In Tocqueville's Shadow: Hannah Arendt's Liberal Republicanism". The Review of Politics 57 (1), 3-158.

Louise-Knott, M. (2015). Unlearning with Hannah Arendt. Trans. David Dollenmayer. London: Granta publications.

Lyotard, J. (1985). Tieto postmodernissa yhteiskunnassa [1979]. Kääntänyt Leevi L. Jyväskylä: Gummerus.
Melville, H. (1995). Billy Budd [1924]. London: Penguin.

Nixon, J. (2015). Hannah Arendt and the Politics of Friendship. London: Bloomsbury.

Proust, M. (1968-2007). Kadonnutta aikaa etsimässä [1913-1927]. Useita suomentajia. Helsinki: Otava.

Rousset, D. (1998). Les jours de notre mort [1947]. Paris: Hachette Littérature.

Taminiaux, J. (1992). La fille de Thrace et le penseur professionel. Paris: Payot.

Tsao, R. (2002). "Arendt Against Athens: Rereading The Human Condition". Political Theory 30 (1), 97-123.

Villa, R. D. (1996). Arendt and Heidegger - The Fate of the Political. New Jersey: Princeton University Press.

Young-Bruehl, E. (2013). Hannah Arendt: Leben, Werk und Zeit [1982]. Kääntänyt Hans Günter Holl. Frankfurt am Main: Fischer.

Wolin, R. (2003). Heidegger's Children [2001], New Jersey: Princeton University Press,

Zizèk, S. (2002). Did Somebody say Totalitarianism?. London: Verso.

Zizek, S. (2012). Less Than Nothing. London: Verso. 
1. Arendtin kulttuuria käsittelevät lyhyemmät kirjoitukset on koottu postuumisti julkaistuun teokseen Reflections on Literature and Culture (2007) ja Arendtin filosofiset henkilökuvat löytyvät teoksesta Menschen in finsteren Zeiten (1989). Kulttuuri ja taide ovat kuitenkin esillä jossain muodossa käytännössä Arendtin kaikissa merkittävimmissä teoksissa. Arendt itse kuvailee taiteen merkitsevyyttä itselleen esimerkiksi usein siteeratussa Gauss-haastattelussa vuodelta 1964, ks. Arendt (2012b, 46-72)

2, Runouden erityisestä merkitsevyydestä Arendtille kertoo myös se tosiasia, että Arendt itse kirjoitti runoja. Nämä on julkaistu postuumisti teoksessa Ich selbst, auch ich tanze - die Gedichte (2015).

3. Arendtin suhteesta kirjallisuuteen, taiteeseen ja mainittuihin taiteilijoihin ks. erityisesti Kristeva (1999), Hahn \& Louise-Knott (toim.) (2007) ja Heuer \& Von der Lühe (toim.) (2007). Taiteen ja taitelijoiden merkittävyydestä Arendtille henkilökohtaisella tasolla ks. Young-Bruehl (1982).

4. Koska Arendtin teosten englannin- ja saksankieliset versiot eroavat toisistaan paikoin hyvinkin paljon, olen tarpeen vaatiessa viitannut kumpaankin laitokseen. Arendt käänsi itse tärkeimmät työnsä saksan kielelle ja näitä käännöksiä voidaan perustellusti pitää myös täydennyksinä "alkuperäisille", englanninkielisille teoksille. Kielen merkityksestä Arendtille ks. esim. Tsao (2002), Brauer (2011) ja Knott (2011). Kaikki artikkelissa olevat suomennokset englannista ja saksasta ovat omiani.

5. Arendtille 1900-luvun kaksi "fundamentaalista kokemusta" ovat nimenomaan totalitaaristen hallintomuotojen nousu sekä atomipommien kehittyminen. (vrt. Arendt 1989, 6; Arendt 2005, 109-110; Arendt 2015, 14-15). Kuten tulemme näkemään, myös Arendtin kulttuuripoliittinen ajattelu lähtee liikkeelle näistä tapahtumista.

6. Arendtia onkin ongelmallista tulkita Karl Popperin tapaisena liberaalina poliittisena ajattelijana, kuten esimerkiksi Slavoj Zizek (2002, 2012) on tehnyt. Arendt myös itse eksplisiittisesti kieltää olevansa liberaali (Arendt 2012b, 124).

7. Tulkinnat Arendtista uusrepublikaaniseen perinteeseen kuuluvana ajattelijana (ks. esim. Canovan 1992, Lloyd 1995, Nixon 2015) ovat siinä mielessä osuvia, että ne tunnistavat modernin maailman moniulotteisuuden Arendtin ajattelussa.

8. Arendtin suhteesta Aristoteleeseen ks. esim. Villa (1996, 17-41) ja Backman (2010).

9. Arendtin teokset The Human Condition, Between Past and Future (1961) ja On Revolution (1963) heijastelevat kaikki pienin variaatioin samaa historiallista narratiivia länsimaisen ajattelun ja kulttuurin synnystä, jota Arendt kehittelee myös ajattelupäiväkirjassaan Denktagebuch 1950-1973, sekä muissa hänen elinaikanaan julkaisemattomaksi jääneissä teksteissä. (Ks. Arendt 1993; 2002; 2005).

10. Ks. Villan ja Benhabibin vuoropuhelu Arendtin ja Nietzschen suhteesta, Villa (1996, 67-72) ja Benhabib (2003, xiv-xviii, 195-197).

11. Jätän tässä tarkoituksella Arendtin 1930- ja 1940-luvuilla kirjoittamat varhaiset juutalaiskysymystä ja juutalaisuutta käsittelevät esseet vähäiselle huomiolle, sillä näiden kirjoitusten pääpaino on nimenomaan juutalaisuutta koskevassa kulttuurihistoriassa ja poliittisissa kysymyksissä, kun taas Arendtin myöhemmät teokset tarkastelevat länsimaista kulttuurihistoriaa ja ajatteluperinnettä kokonaisvaltaisemmassa mielessä. Arendtin varhaiset esseet on koottu teokseen The Jewish Writings (2007).

12. Arendtille juuri marksismi - toisin kuin kanssallissosialismi, jota Arendt pitää alusta asti filosofisesti halpana ideologiana - näyttäytyy länsimaisen poliittisen ajattelun tradition viimeisenä suurena yrityksenä vastata 1900-luvun poliittisiin haasteisiin: "Marksismi oli yritys vastata uusiin kysymyksiin suuren tradition keinoin. Siksi lokakuun vallankumous oli 1900-luvun suuri toivo, ja siksi se tosiasia, että myös tämä tie päätyi totalitaarismiin [on] aikakauden olennainen pettymys,..., [koska] suuri traditio itse johti tähän, täytyy itse länsimaiden (Abendlandes) kaikessa poliittisessa filosofiassa olla jotain perustavan virheellistä." (Arendt 2003, 253-254).

13. (Vrt. Arendt 1978a, 12; Arendt 2006a, 6; Arendt 2006b, 207; Arendt 2012b, 125.)

14. Arendtin näkemys länsimaisen tradition katkeamisesta tulee hyvin lähelle Jean-Francois Lyotardin näkemyksiä teoksessa Tieto postmodernissa yhteiskunnassa (1979). Lyotardin tun- 
netun näkemyksen mukaan "postmodernin" aikakauden keskeinen piirre on juuri "suurten kertomusten" merkityksen katoaminen. Modernin lopun teemasta filosofian parissa, ks. myös. Habermas (1988), Badiou (1989; 2009) ja Latour (1991).

15. Narrativiteetin merkityksestä Arendtin ajattelulle, ks. erityisesti Kristeva (1999) ja Benhabib (2003).

16. Arendtin mainittu tulkinta Kafkan Linnasta löytyy esseestä "The Jew as a Pariah: A Hidden Tradition (1944/2007b, 275-297)” ja mainittu analyysi Brochin romaanista kirja-arvostelusta "No Longer and Not Yet (1946/1994b, 158162)".

17. Ks. Arendt (1994a, 80-88). Arendt toteaa että Proust on kaikkein paras todistaja "aikakaudesta, jolloin yhteiskunta oli vapautunut kokonaan julkisista huolista ja jolloin politiikka itse oli muodostumassa osaksi sosiaalista elämää" (Arendt 1994a, 80).

18. Kyseinen teos on Arendtin mukaan "kaikkein valaisevin teos rotukokemuksesta Afrikassa" (Arendt 1994a,185).

19.Ks. erityisesti Arendt (1994a, 440-441). Eräässä myöhemmässä tekstissään, jossa Arendt vastaa Eric Voegelinin kritiikkiin teoksesta The Origins of Totalitarianism, Arendt toteaa nimenomaisesti, että hän poikkeisi kyseisessä teoksessaan tietoisesti klassillisesta historiankirjoituksen perinteestä. Juuri keskitysleirit muodostavat sellaisen tutkimuskohteen, jota ei yksinkertaisesti voida lähestyä sine ira et studio, sillä perinteiset sosiologiset tai psykologiset selitykset tuntuvat täysin riittämättömiltä suhteessa keskitysleirien järkyttävään todellisuuteen. Juuri tässä mielessä Arendt sanoo, että hänen kuvauksensa tuhoamisleireistä "maanpäällisenä helvettinä" ei nimenomaan ollut allegorinen tai retorinen väline, vaan aiheen itsensä vuoksi $o b$ jektiivisin mahdollinen kuvaus (Arendt 1994b, 402-404; vrt. Arendt 1994a, 445). Samasta syystä Arendt myös vetoaa kuvauksissaan keskitysleireistä toistuvasti Roussetin kuvaukseen.

20. Ks. Arendt (2006b, 72-79).

21. Terminä "radikaali paha" tulee Immanuel Kantilta. Arendt luopui kyseisestä termistä ja aiemmin käyttämästään "absoluuttisen pahan" käsitteistä 1960-luvun alussa. (vrt. Arendt 1978. 190-191; Arendt 1992, 17; Arendt 1994a, 459; Arendt 2003, 95; Arendt \& Scholem, 444).
Arendtin pahuuden käsitteestä ks. erityisesti Louise-Knott (2015, 3-29).

22. Vrt. (Heidegger 2006, 1; Heidegger 2007, 19; Arendt 2012b, 186-187).

23. Tämänkin näkemyksen Arendt lainaa Heideggerilta, joka puolestaan viittaa Aristoteleen tunnettuun näkemykseen runouden ja filosofian samankaltaisuudesta ks. Arendt (1978a, 8).

24. Arendtin argumentit esteettisen arvostelukyvyn, julkisen tilan, kulttuurin ja taiteen suhteista eivät ole täysin johdonmukaisia. Tämä johtuu suurelta osin siitä, että Arendtin äkillisen ja varhaisen menehtymisen vuoksi hänen viimeinen teoksena The Life of the Mind jäi ratkaisevalla tavalla keskeneräiseksi. Tästä syystä tyydyn vain mainitsemaan esteettisen arvostelukyvyn ja politiikan läheisen suhteen Arendtin ajattelussa.

25. Tämä nimenomaan ei ole positio, joka relativisoisi kaikki narratiivit samanarvoisiksi. Arendtille totalitaarinen narratiivi, joka perustelee itsensä luonnolla tai historialla, on nimenomaan koko todellisuuden selittävä ja inhimillisen moneudellisuuden perusluonnetta vääristelevä kertomus, joka voidaan kertoa vain yhden ainoan kerran yhdestä, absoluuttisen loogisesta näkökulmasta. ks. Arendt (1994a, 469-473).

26. Ks. loppuviite 14 .

27. Ks. Benhabib (2003, ix). 